Mesopotamia Journal of Agriculture

https://magrj.mosuljournals.com

\title{
ECONOMIC ANALYSIS OF GRAPE PRODUCTION FARMS IN SALAH EL-DIN GOVERNORATE FOR THE 2019 PRODUCTIVE SEASON (BALAD DISTRICT AS A MODEL)
}

Zwaid F. Abd

Department of Agriculture Economy- College of Agriculture and Forestry- University of Mosul

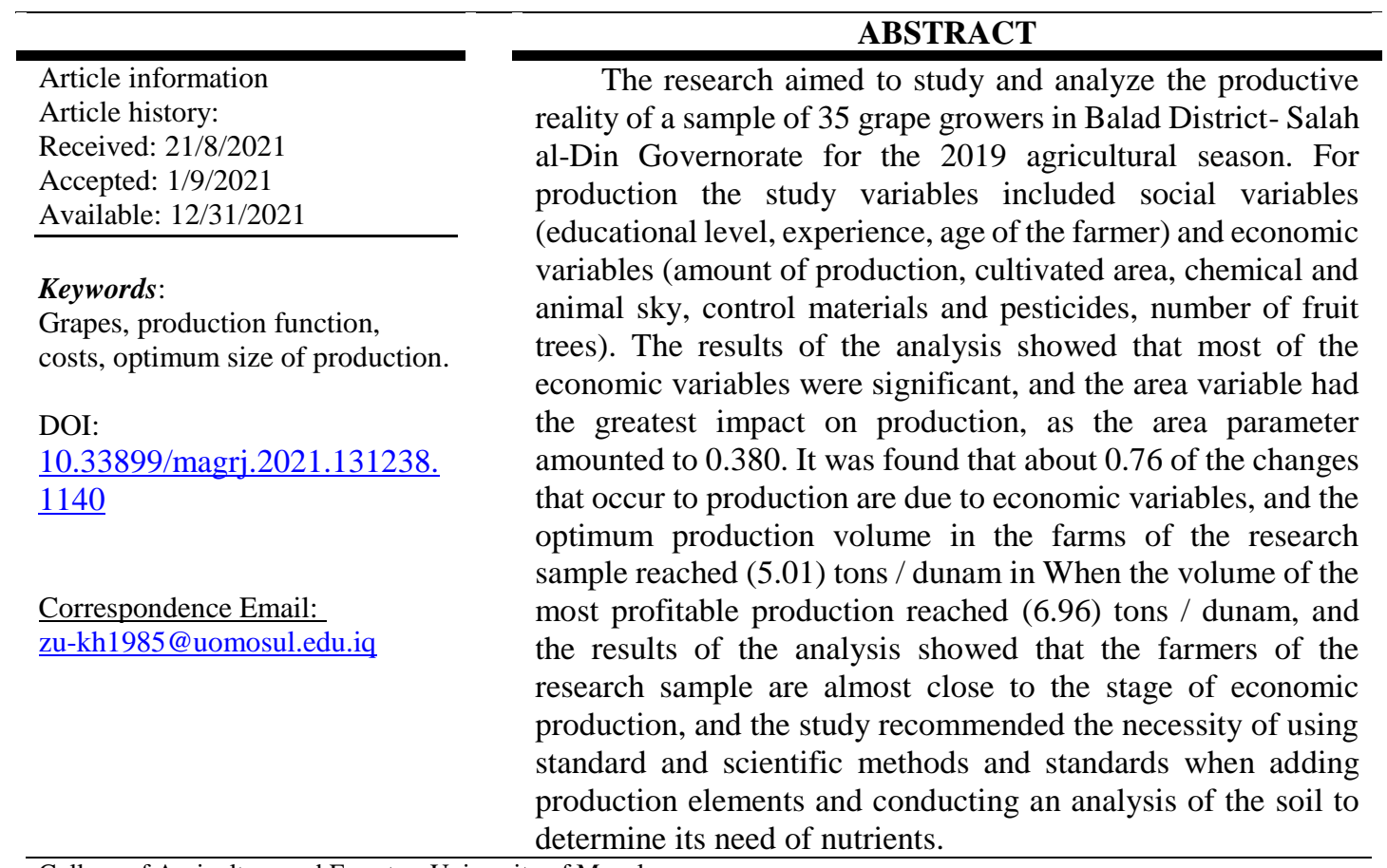

College of Agriculture and Forestry, University of Mosul.

This is an open access article under the CC BY 4.0 license (https://magrj.mosuljournals.com/ ).

\section{INTRODUCTION}

Grapes are considered one of the most productive fruit crops in the world, producing about 67.5 million tons annually, and they grow best in the Mediterranean climate (Khoshroo et al., 2013).Grapes are one of the important summer crops, whether in Iraq or the world, with great economic importance and high nutritional value. They are associated with many food industries, as well as being suitable in the exploitation of agricultural lands unsuitable for planting other fruit trees. Grapes are ranked first among the different fruit trees in terms of production and cultivated area, as the cultivated area in the world is estimated at about $(8291,220)$ hectares and the total production is $(74,584,600)$ tons (World Food Organization, 2007), Regardless of the potential of grapes, farmers face production, processing and marketing problems(Kalimang asi, et al., 2014) Agricultural economists, most notably the study of prices in terms of the purchasing power of the consumer and the producer's obtaining remunerative prices that bring him income (Ferris, 1998). Also, determining the ideal location 
of the farm is important, and the fixed and variable costs that result from the construction operations, as well as the costs of fertilizers, pesticides, etc. (Bordelon, 2001) As one kilogram of table grapes costs four times that of wine grapes, in addition to the high costs of harvesting (marketing operations costs) in relation to the case of table grapes (Conradie, 2006)., The number of grape species is estimated at about 700. (Al-Saidi, 2014) Of them, about (70) types are grown in Iraq, and most of them are concentrated in northern Iraq (abdul-Qader, 2006). Most of the grape varieties grown in Iraq belong to the Vibes Vinifera type. The number of fruit trees in Iraq in 2019 was estimated at about 355 thousand trees, with an average production of about (123). ) thousand tons (the Arab Organization for Agricultural Development 2018), and grapes constitute about $(50.53 \%)$ of the total production of summer fruit trees in Iraq The cultivation of grapes is concentrated in most of the governorates of Iraq, and Salah al-Din governorate occupies the first place in terms of area and production. $\mathrm{kg}$ and the highest average productivity was achieved in Diyala governorate during the study season, where the productivity of one tree was estimated at about (39.80) kg, and Dohuk governorate came in second place, and grape cultivation is widely spread in the governorates of Diyala and Najaf ( $\mathrm{Al}$ Saidi ,2014).

The district of the country of the research sample occupies the first place among the districts and sub-districts of Salah al-Din Governorate, and many varieties are grown in the farms of the research sample and the most varieties are cultivated by Kamali, Halawani and local black. The problem of the research is that despite the occupation of Salah al-Din Governorate first in terms of production and the area planted with grapes, and the farmers' possession of experience and management in the exploitation of the economic resources used in the production of grapes, but the productive reality indicates that the quantities produced and the exploitation of economic resources did not achieve the production and economic efficiency and thus the decrease in the agricultural yield of the farms of the research sample, and this is considered an indicator of the deterioration of the cultivation and production of this crop The research is based on the hypothesis that the actual production of the grape crop in the farms of the research sample may move away from the optimal production situation achieved for production efficiency and deviate from the maximum production of profits . The research aimed to analyze and study the productive reality of vineyards in Balad district for the 2019 productive season by estimating the production and costs functions, including determining the optimum size and maximal volume of profits. For the importance of the grape crop in terms of economic and food terms, many specialists were interested in studying the economic and technical aspects. Many studies and researches related to production aspects, costs, income and revenues. from which to study ( $\mathrm{Al}$ Yuzbaki et al. , 2008) indicated that the production volume of chickpea crop of $160 \mathrm{~kg} /$ dunum is at a higher level than the optimum volume of production of $140 \mathrm{~kg} /$ dunum and below the volume of the maximum production of profits, where the average profit obtained by the farmer is 96080 dinars / dunum. were published (Zikrullah et al., 2011) studied the economic analysis of grape, grain 
and vegetable production systems in urban and semi-urban agriculture in Kabul, and the study aimed to verify the profitability of farms, including grape farms, and the study included 100 families and the studied sample included (12) producers of the grape crop, and the results of the analysis showed The vineyards achieved the lowest returns with a revenue of about (5400) US dollars / hectare. And (Gordana, 2012) conducted an analysis of the technical efficiency of family farms producing grapes in the Republic of Macedonia, and the study aimed to determine how farmers' performance affects the production of Macedonian grapes and to determine the most efficient use of resources and knowledge of the administrative capacity of farmers and productive seasons 2006-2008, and the results of the analysis indicated the possibility of making improvements Great on efficiency with a potential cost reduction of $29 \%$, farm revenue could be improved by $47 \%$, and younger farmers achieved more technical efficiency And (Ali et al., 2012) published a research entitled Determining the technical efficiency and risk of grape production farms in the sistan and for the agricultural year 2010-2009 and for a sample of 265 farmers using the stochastic frontier analysis method, and the results showed that the average technical efficiency of the sample amounted to $80 \%$ and that the experience and the area of the farm It has a greater impact on the technical efficiency in the farms of the research sample. . While explained (Ahmed, 2012) the contribution of each of the labor and capital suppliers in order to maximize the profit from the production process, where the optimal amount of work amounted to 4 workers / day and the optimal amount of capital was 7,182.56 dinars / dunum. $2115.67 \mathrm{~kg}$. And (Vairam and Munivanda,2013) studied the economic analysis of grape production and marketing in the province (Theni)The sample included a research group of grape growers during the agricultural season 2008-2009 and it was found that the Teny region contributes about $85 \%$ of the total share of grape production in Tamil, and the production of one acre amounted to 6.500 kilograms, and he determined that the farmers face problems, the most important of which is the lack of a rewarding price Because of their products and their inability to protect grape trees from diseases and pests, the study recommended the need to open agricultural clinics to combat pests and diseases, provide cold stores and support grape prices . In 2018, (Natalia, et al,2018) studied the economic analysis of grape production and marketing for small farmers in Dodoma County, with the aim of evaluating the production and marketing of grape producers and a sample of 35 producers using the SPSS, MC-Exeel programs, and the results indicated that the owners of small farms were more efficient than the owners of small farms Other farms and that most of the farmers who practice grape cultivation have a low level of education, were published Shebel ( 2020) study also referred mainly to a standard analysis of changes in the most important factors that are supposed to affect the production of the sugar cane crop and sugar beet in Egypt during the period 2001-2007, where the results showed that changes in the instability coefficients of the cultivated area and productivity explain about 50\% From the economic stability of sugar cane production, and a change of $10 \%$ in those variables leads to a change in the economic stability of sugar cane production about $2.3 \%$ and $5.4 \%$, respectively. 


\section{MATERIALS AND METHODS}

To achieve its objectives, the study relied on the preliminary data for the 2019 production season. The study covered a random sample of grape growers in the Balad region, as it is the largest area in terms of area and production of grapes, amounting to (35) farms. The cultivated areas ranged between a minimum of (2) dunums and a maximum of (12) dunams, The data were collected in personal interviews through a questionnaire prepared for the purpose of achieving the objectives of the research, which included some social variables such as (educational level, experience, age of the farmer) and economic variables (amount of production, cultivated area, chemical fertilizers, control materials and pesticides, animal manure, and the number of fruit trees). The questionnaire covered an area of 154 dunums with an average capacity of (4.4 dunums / farm, while the total production during the study season for the farms of the research sample reached (718) tons and an average of (20.51) tons / farm, and thus the average production of one dunum was (4.66) tons / dunum and is cultivated Many varieties in the research sample area, the most of them are Kamali, Halawani, olive and local black. The standard model that represents the data of the research sample was chosen using the methods of descriptive statistical analysis and the method of quantitative economic analysis by estimating the regression model of the production function and by many formulas (logarithmic, half-logarithmic and linear) and the regression model Non-linearity in the quadratic and cubic form of cost functions and the derivation of marginal and average costs, including determining the optimum size and the maximal size of profits. . The ability of the parameters of the variables by the method of ordinary least squares (OLS) and the significance of the variables and the function were tested using the statistical tests $(\mathrm{t}, \mathrm{f})$ and the adjusted coefficient of determination $\left(\mathrm{R}^{-}\right)$to show the explanatory power of the independent variables and their impact on the dependent variable, and standard tests were used to detect the problem of self-correlation between random errors. Accompanying the exploited variables, the Durban Watson (DW) test was adopted, and the value and indication of the variables parameters for the economic tests and the extent to which the effect of these explanatory variables corresponded with the concepts of economic theory was adopted, and with the aim of analyzing grape production in a sample of research farms during the productive season 2019 and using the multiple regression model in Estimating and analyzing the production function with the following formula:

$$
\mathrm{Y}=\mathrm{Bo}+\mathrm{B} 1 \mathrm{X} 1+\mathrm{B} 2 \mathrm{X} 2+\mathrm{B} 3 \mathrm{X} 3+\mathrm{B} 4 \mathrm{X} 4+\mathrm{B} 5 \mathrm{X} 5+\mathrm{B} 6 \mathrm{X} 6+\mathrm{Ui}
$$

Thus, the variables included in the model (1) above can be determined, as

$\mathrm{Y}=$ Production Quantity (tons)

$\mathrm{X} 1=$ Cultivated area (acres)

$\mathrm{X} 2=$ Number of workers (worker/season)

$\mathrm{X} 3=$ fertilizer $($ ton)

$\mathrm{X} 4=$ control materials and pesticides (liters)

$\mathrm{X} 5$ = animal manure (tons)

$\mathrm{X} 6=$ number of fruit trees (tree)

$\mathrm{Ui}=$ random limit 


\section{B1,B2,B3.B4,B5,B6 = Model parameters}

In order to achieve the objectives of the research, it was necessary to adopt and test many formulas for production and cost functions, using the linear, logarithmic and half-logarithmic model for the production function, and the linear, quadratic and cubic formula for the cost function.

\section{RESULTS AND DISCUSSION \\ The results of the production function analysis of the grape crop in the farms of the research sample}

Based on the best estimates and based on the indicators of economic theory and statistical and standard criteria, it was found that the double logarithmic picture was the one that gave the best results to represent the relationship between the volume of grape production as a dependent variable and the factors affecting production as explanatory variables, and the following picture was taken:

$\log \mathrm{Y}=2.36+0.380 \log \mathrm{X} 1+0.371 \log \mathrm{X} 2+0.183 \log \mathrm{X} 3+0.0062 \log \mathrm{X} 4+$ $0.061 \log X 5+0.271 \log X 6---(2)$

$\left(\mathrm{t}^{*}\right) \quad(3.36)$

$(-1.14)$
R-sq=81.1
$R-s q(\operatorname{adj})=76.4$
$\mathrm{F}=9.92$
$\mathrm{D}-\mathrm{W}=2.26$

The double logarithmic function (Equation 2) shows that there is a significant effect of each of the cultivated area $\mathrm{x} 1)$, the number of workers (x2), the chemical fertilizer (x3), the control materials variable $(\mathrm{x} 4)$ and the number of trees variable $(\mathrm{x} 6)$ on the volume of grape production in the farms of the research sample. The variable cultivated area has a positive significant effect, and the elasticity of this variable has reached 0.380 , meaning an increase in the cultivated area by $1 \%$ leads to an increase in the volume of production of grapes by $0.380 \%$, while it was found that there is a significant positive effect of the variable number of workers on the volume of production through a sign And the value of the parameter of this variable amounted to 0.371 , which means that any change in the number of workers will lead to a change in the quantity of grape production whose value is equal to the value of the parameter. Equation (2) shows that there is a positive and moral effect of the chemical fertilizer Heath variable. The value of the elasticity of this variable is 0.183 with a positive sign. It means when adding an amount of chemical fertilizer by $1 \%$, it leads to an increase in the production quantity of grapes equivalent to the elasticity value of this variable representing 0.183, and through the values of Estimated parameters It turns out that the variable of the control materials has a positive effect, but in a small percentage compared to the rest of the variables, where the productivity flexibility for this variable reached 0.0062 , and the estimated function shows that the variable number of fruitful trees has a positive effect on the amount of grape production, where the productivity flexibility for this variable reached 0.271. While the effect of the animal manure variable (X5) was negative on the amount of grape production, which indicates that the addition of animal manure by $1 \%$ 
leads to a decrease in the amount of grape production equivalent to the value of the productive flexibility of $0.061 \%$ and this is contrary to the concepts of economic theory and can be Explanation of the inverse relationship between animal manure and the amount of grape production to the misuse of animal fertilizers, as well as the farmers' failure to conduct analyzes of the nutritional components of the soil and know the extent of its needs for the production elements present in animal manure. The value of the modified determination coefficient, which amounted to $76 \%$, indicates that the explanatory variables The study explains about $76 \%$ of the changes in the quantity of grape crop production, while the rest of the changes that occur in the production quantity are due to other variables that were not included in the estimated model, and the calculated $\mathrm{F}$ value indicates the significance of the model as a whole. In order to clarify the problem of autocorrelation between random variables, Durbin Watson's (DW) test was adopted, and through the estimated model, it became clear that the calculated (DW) value amounted to (2.26), which is greater than (4-d2) estimated, which confirms that there is no autocorrelation between the variables. In order to make sure that $t$ here is no multicollinearity between the explanatory variables, Klein's test was adopted and by taking the square root of the coefficient of determination and comparing it with the partial correlation coefficients, it was found that it is greater than the values of the simple c By noting the productive elasticities of the economic variables, we note that the variable of the cultivated area has the greatest impact on the amount of grape production, and the number of workers variable came in second place in terms of the positive impact on the amount of grape production, while the least positive impact was on the variable of control materials on grape production, and it was also clear from equation (1). The total production elasticities amounted to 1,150, which is positive and greater than the correct one. Thus, farmers' production is almost approaching the end of the first stage, meaning an increase in the production elements combined leads to an increase in the quantity of production with increasing increases. Therefore, the increase in the production elements combined and by $1 \%$ leads to an increase The production quantity is $1.150 \%$, (Gujarati, 2004).

The results of the analysis of the cost function of grape production in the farms of the research sample

To determine the pattern of the relationship between the total costs of grape production and the volume and quantity of production in the farms of the research sample, cost functions and many formulas (linear, square, and cubic) and using simple and multiple regression method were used in the analysis And estimating the relationship between the amount of production and the amount of costs for the grape crop and based on the indicators of economic theory and statistical and standard criteria, and by studying the relationship between the amount of production of grapes and the total costs of the farms of the research sample, it was found that the cost function in the quadratic form is more expressive of the relationship from the economic and statistical aspects and took the following formula:

$C_{i}=1941.16+305 y+3.99 Y^{2}$ 
$\mathrm{t}^{*}(2.52)$

$$
\mathrm{R}^{2}=87.1
$$

$$
\mathrm{R}-\mathrm{S}(\operatorname{adj})=85.2
$$

\section{$\mathrm{D}-\mathrm{W}=1.54$}

So: $\mathrm{CI}=$ total costs (ID) and $\mathrm{Yi}=$ production quantity (tons).

It is clear from the results of the statistical analysis of the cost function equation (3) for the grape crop in the farms of the research sample that the significance of the estimated function through the calculated $\mathrm{F}$ value, which exceeded its two tabular counterparts at a significant level of $5 \%$, is confirmed. $85 \%$ of the changes in the amount of costs, in other words, the fluctuations in total costs are due to the production volume variable, and $15 \%$ are explained by other factors not included in the model. The statistical significance of the production volume variable and the production volume squared depends on the calculated and compared ( $\mathrm{t}$ ) test $\mathrm{b}(\mathrm{t})$ tabular at 5\% significance level and NK degrees of freedom, where $\mathrm{K}$ is the number of variables The research and $\mathrm{n}$ number of observations, and the value of the adjusted coefficient of determination indicates that the volume of production explains about $(85 \%)$ of the change in the total costs of the grape crop. Autocorrelation) between the random variables The Durbin Watson (DW) test was adopted, and through the estimated model, it became clear that the calculated (DW) value amounted to (1.54) and this calculated value is located within the critical region, which confirms that there is no self-correlation between the random variables, and to make sure that there is no correlation Multicollinearity among the explanatory variables A test was adopted.By taking the square root of the coefficient of determination and comparing it with the partial correlation coefficients, it was found that it is greater than the values of the simple correlation coefficients in the matrix of partial correlation coefficients (Gujarati, 2004).

Estimation and analysis of the optimum and maximal volume of profits for grapes in the farms of the research sample:

1- Estimation of the optimum size of grape production farms: the optimum volume is that volume of output that can be obtained at the lowest cost, and represents the civil size of costs. At this level, the value of the productive resources needed to produce one unit of production is possible Costs, and by using the derivatives of the grape crop costs function equation (3) and by equating the marginal costs function with the average costs function, we get the optimum volume of grape production in the farms of the research sample as follows:

$\mathrm{MC}=305+7.98 \mathrm{Y}---------------4($

$\mathrm{AC}=1941.16+305 \mathrm{Y}+3.99 \mathrm{Y} 2 / \mathrm{Y}$

Then $\mathrm{MC}=$ marginal cost and $\mathrm{AC}=$ average cost, and by equating the marginal cost equation with the equation of the average cost function and as follows:

$305+7.98 \mathrm{Y}=1941.16=305 \mathrm{Y}+3.99 \mathrm{Y}^{2} / \mathrm{Y}$

By solving equation (4), it was found that the optimal production volume amounted to (22.08) tons for the average area planted in the farms of the research sample, which amounted to (4.4) dunums, and thus the optimal production volume was (5.01) tons / dunums.

2- Estimation of the volume of the maximum profit production for grapes in the farms of the research sample: To estimate the volume of the maximum 
profit production, the marginal principle was applied and by equating the marginal cost $\mathrm{MC}$ with the marginal revenue $\mathrm{MR}$, which represents the price per ton of grapes, which is on average 550 Iraqi dinars, as follows

$\mathrm{MC}=\mathrm{MR}=\mathrm{P}$

$$
305+7.99 \mathrm{Y}=550 \quad \mathrm{Y}=3.66
$$

Accordingly, the volume of production maximizing profits is (30.66) tons for the average cultivated area for each farm, and thus the average volume of production maximizing profits is (6.96) tons / dunam. We conclude from the results of the analysis that the logarithmic production function was more expressive of the relationship between the volume of production and economic variables, and that the cultivated area variable had the greatest impact on increasing production, and that the animal manure variable had a negative impact on the volume of grape production, which contradicts the concepts of economic theory and this is due To increase the amount of this added element and not to conduct analyze of the nutritional soil elements in the farms of the research sample, and it was found through the sum of the total elasticities of the production function variables that the farmers of the research sample are almost close to the economic production stage, while the cost function in the quadratic form is the most representative of the relationship between the total costs and the volume of production for the grape crop, and this means that the farmers are still They have the opportunity to increase their production to reach the volume of production that maximizes profits and the possibility of intensifying production elements, thus raising the production efficiency of the production elements used and bringing production to the economic production stage. Therefore, we recommend following the standard and scientific methods and standards when adding production elements and conducting analyzes of the cultivated soils to install their needs of nutrients to avoid wastage In these items We also recommend the concerned authorities to provide production requirements At reasonable prices, especially pesticides, means of jungle control and wasp bugs, and the need to introduce mechanization and modern technology in grape cultivation and industries.
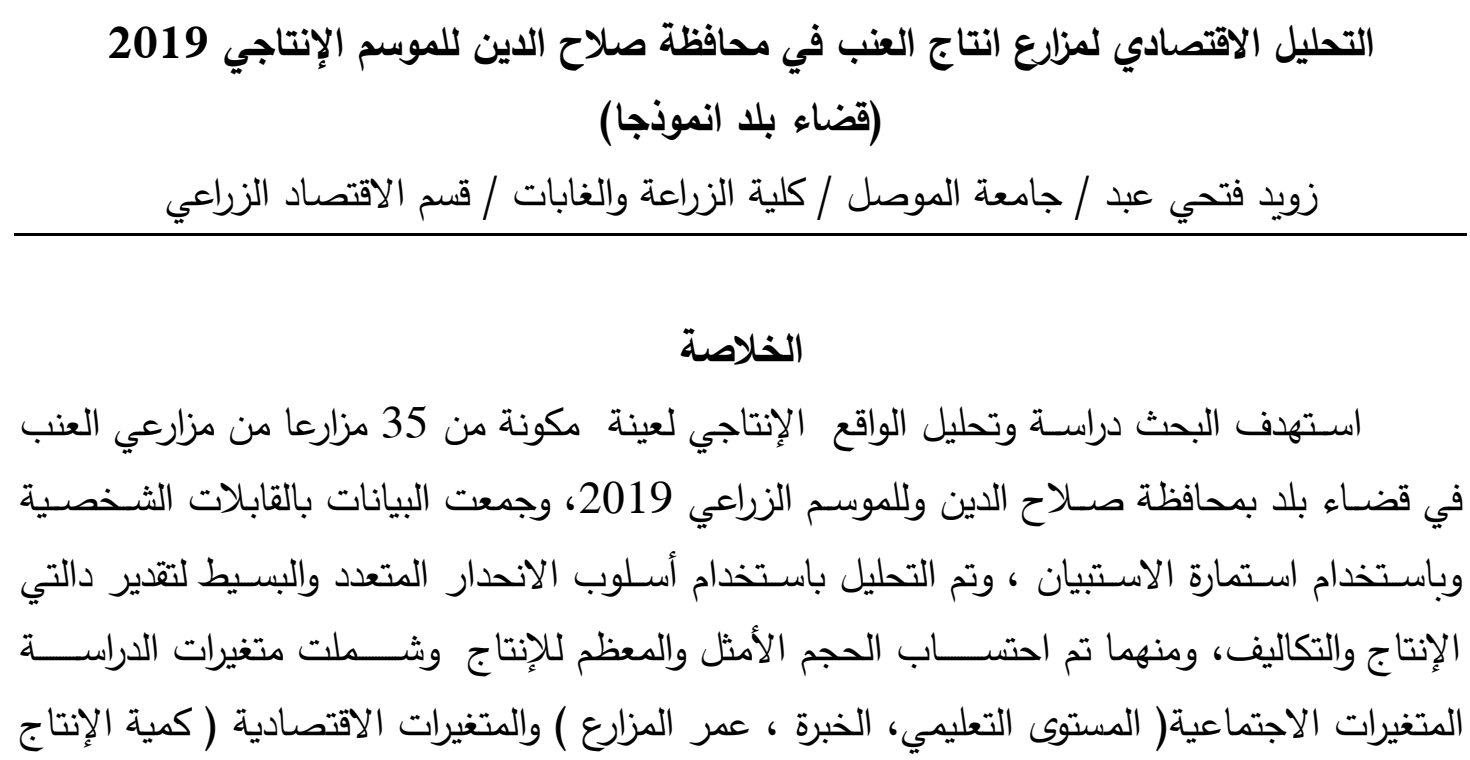
، المسـاحة المزروعة ، السـماء الكيماوي والحيواني ، مواد المكافحة والمبيدات ،عدد الأشـجار المثمرة ) وتبين من نتائج التحليل ثبوت معنوية معظم المتغيرات الاقتصـادية وكان لمتغير المسـاحة الأثر الأكبر على الإنتاج حيث بلغت معلمة المســاحة 0.380 وتبين ان حوالي 0.76 من التغيرات التي تحصـلـ للإِنتاج تعود الى المتغيرات الاقتصـادية ، وبلغ حجم الإنتاج الأمثل في مزارع عينة البحث (5.01) طن

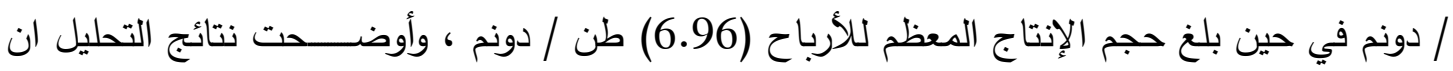
مزراعي عينة البحث يكاد يقتربون من مرحلة الإنتاج الاقتصـادية ، واوصـت الدراسـة بضـرورة اسـتخدام الأسـاليب والمعايير القياسية والعلمية عند إضـافة عناصـر الإنتاج واجراء تحليل للترب لتحديد احتاجها

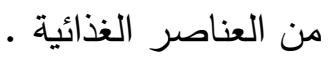
الكلمات المفتاحية : العنب ، دالة الإنتاج ، التكاليف ، الحجم الأمثل للإنتاج

\section{REFERENCES}

Abdul-Qadr ,S.M.(2006) . Effect of Training System Canopy Manag -Cment and Dates on The Yield and Quality of Grape-Vnes CV"Tafi "Vitis Vinifera L. Under Non-Irigated Condition . M.Sc. Thesis . university of Dohuk,p:1-144 Ahmed, I. A. A.(2012). " Economic analysis and the standard function for the production of tomato crop in terms of fresh bath of, nineveh province, the agricultural season 2011"AL-Rafidain Agriculture Journal,.40 (special issue), 73-76

Ali, s. sh., nazar, d. \& Alireza, k (2012) . determining technical efficiency with risk for grape gardens in sistan area by using stochastic frontier analysis, international journal of agriculture: research and review, 2 (5), 1037-1044.

Al-Saidi, I. H. (2014) . Classification of Grapes, Dar Al-Wadah Publishing, The Hashemite Kingdom of Jordan, Amman,p:19-527

Al-Yuzbaki, S. M. Thalaj, A. A. \& Abd, Z. F. (2008) . "An econometric study for the production of chickpea crop in Nineveh governorate for the agricultural sea son/2005"Mesopotamia Journal of Agriculture, 36 ( 1),3335 .

Bordelon, B. (2001). Business Planning and Economics of Midwestern Grape Production. Purdue University, France, http://www. hort. Purdue. Edu/fruitive/fruit/grapes

Conradie, B.G. (2006). Efficiency and farm size in western cape grape poduction:pooling small datasets. South African Journal of Economice, 74(2),334-343.

Ferris, N.J. (1998). Agricultural Prices and Commodity Market Analysis. Michigan University.p:8-347

Food and Agriculture Organization of the United Nations (FAO), http://www.fao.org .

Gordana, M.T. (2012) . Efficiency Analysis of Commercial Grape-Producing Family Farms in the Republic of Macedonia. Ph.D. Thesis , Swedish University of Agricultural Sciences,p:3-361

Gujarati, D,G.(2004).Basic Econometrics.,(4nd ed).McGraw-Higher Education. New York:p1-1037 
Kalimangasi, N., Majula, R., \& Kalimangasi, N. N. (2014). The economic analysis of the smallholders grape production and marketing in Dodoma Municipal: A case study of Hombolo Ward. International Journal of Scientific and Research Publications, 4(10), 1-8.

Khoshroo, A. Mulwa, R., E. \& Arabi, B. (2013): Analysis Approach for Improving Energy Efficiency of Grape Production, energy, htt://dx.doi.org/10.1016/j.energy.

Shebel, A. A. (2020). "An Economic Analysis for Production of Sugar Beet and Sugar Cane Crops in Egypt, Agricultural Economics Research Institute - Agricultural Research Centre , 11 (2),:93-98.

Vairam, R. \& Muniyandi, B. (2013) . An economic analysis of the production and marketing of grape cultivation in Theni District, Tamil Nadu. : International Journal of Research in Commerce, Economics and Management, 3 (9), 14-18.

Zikrullah, S., Hippolyte, D., \& andreas, B.(2011). Economic analysis of cereal, vegetable and grape production systems in urban and peri-urban agriculture of kabul, Afghanistan ,expl agric,47 (4), 705-716. 